\title{
Marriage Choice, Government Size and Political Connection
}

\author{
Shili Chen \\ Jinan University, Guangzhou, China \\ Email: 15521283200@163.com
}

How to cite this paper: Chen, S.L. (2019) Marriage Choice, Government Size and Political Connection. Modern Economy, 10, 624-644.

https://doi.org/10.4236/me.2019.103043

Received: January 31, 2019

Accepted: March 9, 2019

Published: March 12, 2019

Copyright $\odot 2019$ by author(s) and Scientific Research Publishing Inc. This work is licensed under the Creative Commons Attribution International License (CC BY 4.0).

http://creativecommons.org/licenses/by/4.0/

\section{c) (i) Open Access}

\begin{abstract}
This paper investigates the relationship between government size and marriage matching in China, trying to figure out the mechanism how government size makes impact on individuals as well. Based on the data of China General Social Survey in 2013 (CGSS2013), the results show that the enlargement of government scale will make the individuals with family background of cadres more likely to marry those with family background of cadres than those without family background of cadres. This paper points out that the value of cadre family's political connection expands as government size increase, which drives individual with cadre family background to marry with cadre through providing more opportunity and motivation. Besides, this paper further verifies political connection expands with expansion of government size from self-evaluation of the importance of political connection and family income aspect.
\end{abstract}

\section{Keywords}

Political Connection, Government Size, Cadre Family Background, Marriage

\section{Introduction}

Marriage has always been a hot topic in society. For individuals, the choice of marriage is related to individual happiness, while for countries, it affects social harmony and development. Marriage in China has undergone tremendous changes since ancient times. From the "arranged words of parents" in feudal times to the free love advocated in the 21 st century. The voice of both parties in the marriage relationship is getting bigger and bigger, so is the freedom of choice. Nevertheless, marriage is not simply determined by love, especially based on traditional Chinese ideology and culture. Marriage is often influenced by many factors such as family background, career, and personal future develop- 
ment.

"Who marries whom" is a classic topic in social science nowadays, that is, marriage matching. The study of marriage matching can not only make us realize the inextricable relationship between various factors and marriage, but also reflect the development of stratified pattern and values in today's society. In recent years, the family of officials and cadres has attracted more and more attention from the public, and the behavior of children born in this family has often become a hot social issue. This phenomenon is caused by historical reasons and related institutional factors. Domestic and foreign media have never spared space in reporting related events. For example, "My father is Li Gang" incident quickly occupied the front page of the International Herald Tribune. The frequent outbursts of relevant reports, coupled with media rendering, have caused the public to have a more negative evaluation of the group. There is no doubt that such problems are not only related to the image of the government and social justice and order, but also to China's international image. In addition, the number of children born in cadre families is much larger than we imagined. According to the data of China's comprehensive social survey, the number of parents in public institutions and government departments reaches $15-25 \%$. In addition, the data show that the proportion of children of cadres among the people who marry individuals in government departments and public institutions is $30.5 \%$, which is a fairly high proportion. At the same time, $34.23 \%$ of cadres' children inherit their father's career. To a certain extent, this phenomenon shows that the marriage of cadres' children and individuals working in government departments has gone beyond the scope of career matching, and there are more factors affecting this kind of "marriage" behavior. What are the key factors affecting the marriage of children born in official cadres' families and their marriages are different from those of children born in ordinary families? This is a question worthy of our study. When it comes to cadres and families, they have to relate to the size of the government.

Government size refers to the sum of all the specific components of the government based on the allocation of functions and powers and constructed according to certain organizational principles. It includes two parts: internal scale (functions, powers) and external scale (institutions, personnel, expenses). The internal scale determines the external scale. The basic criteria for evaluating the rational scale of government are leanness, efficiency, coordination and integration, and consistency with financial resources.

Government size has always been an important area of economic research. From both theoretical and practical perspectives, the issue of government size is closely related to the status and efficiency of the government, the origin of the country and corruption. To some extent, the study of government size is also the study of the necessity of the existence of government. In contemporary economic society, the role of the government in economic operation is no longer confined to the "visible hand" in traditional economic theory. The government plays an important role in economy, culture, value orientation and many other as- 
pects. As a big socialist country, China pursues the system and system of socialist market economy. The role of government is particularly special. After the reform and opening up, although the market plays a more and more important role in the economic operation, the function of the government is to influence the operation of the whole country more widely and deeply. Take government expenditure as an example. Since 1978, government expenditure has increased at an alarming rate, from 11.2 billion yuan to 15.033 .5 billion yuan, an increase of more than 100 times. The proportion of fiscal expenditure to GDP is also increasing year by year. At present, China is in the primary stage of socialism. Many problems, such as social order, cultural life, medical education and so on, need the correct guidance of the government so as to meet the growing material and cultural needs of the people. So in addition to economic life, the Chinese government also plays the role of "social rule maker" in all aspects. This also makes the study of government scale-related issues more and more necessary. In 1994, China implemented the reform of tax distribution system, which has a great impact on the relationship between local tax revenue and central tax revenue. Specifically, the tax categories are divided into central tax, local tax and local central shared tax. After the reform, local governments have more control over financial resources, and the scale of government has been expanded due to the reform of fiscal decentralization [1]. The government expenditure as a measure of the proportion of local GDP, since 1996, the scale of the government has maintained the trend of expansion. With the expansion of the size of the government, our social and economic life is bound to continue to expand.

This paper tries to analyze and study whether the size of government affects the marriage choice of children of cadres' families as we imagine, and through what mechanism. Different from traditional study of marriage, this paper focus on macro factors and study how macro factor affect micro individual. Besides, individual form cadre family is a topic of great public concern in china and what role government plays in their marriage matching process, which may be ignored in previous study and it's the value of this paper.

This article is organized as follows: Section 2 is the literature review; Section 3 is the data and key definition. Section 4 is the model and empirical analysis. Section 5 is the conduction mechanism and empirical analysis. Section 6 is the robustness check. And the final is the conclusion.

\section{Literature Review}

\subsection{Foreign Studies}

There are two mature theoretical systems for the study of marriage matching in foreign countries.

Modernization theory:

According to the modern theory of marriage matching, with the continuous development of society, the traditional family and the state gradually lose control over individual spouse selection, while the pre-endowed characteristics (such as 
family economic status, parents' occupation, race, religion, etc.) have less and less influence on marriage, while the self-induced factors (such as personal education level, work experience) have more and more influence [2]. The theory predicts that with the expansion of opportunities and the improvement of population mobility, cross-racial and Cross-religious marriages will become very common in modern society, and the proportion of heterogeneous marriages based on self-induced factors will rise.

The theory of inequality:

The unequal distribution of resources will also affect people's preferences and opportunities for spouse selection. First, inequality affects people's preferences for spouses. The higher the degree of social inequality, the greater the loss of marrying down. At this time, homogeneous marriage instead of heterogeneous marriage has become the mainstream of society. Researchers on educational homogeneous marriage found that when the educational return was high, the proportion of educational homogeneous marriage was also high [3]. Secondly, inequality also affects people's chances of choosing spouses. For example, the more severely segregated the residential areas, the more restricted the opportunities for interaction between different classes, and the higher the homogeneity of marriage may be.

Foreign scholars Goode and Haller found that in the process of marriage matching in traditional society, families in higher social classes tend to encourage their children to choose spouses in their own class, reflecting a fairly strong "door-to-door" concept of spouse selection. In this way, the control of marriage more or less forms a class barrier, which hinders the individual marriage choice of different classes, that is, the so-called "high-climbing" marriage. As a result, such a marriage matching system has become a tool to maintain the social class status and enhance the cohesion within the class.

Burdett, Coles proposed that in general, both parties in the process of marriage matching have preferences for choosing objects of the same class, but when individuals are heterogeneous and their utility is not transferable, there is multiple equilibrium in marriage matching. Abramitzky et al. [4] also proposed a similar view. He believed that in society, the gender ratio is unbalanced and the dominant party tends to be upward marriage. Goldscheider, Waite also discussed the inconsistency in the division of labor based on gender roles in traditional societies: men play a more important role in the family, while women play a more important role in educating their husbands and children. Women prefer to look for men with higher education as spouses, while men do the opposite. In addition, Kerr and Treiman pointed out that, on the basis of the theory of modernization, the proportion of pre-endowment and self-induction matching would decrease under the influence of love and industrialization in modern society.

Foreign scholars have done relatively little research on marriage in China. In the aspect of spouse selection, Chinese traditional culture attaches great importance to the pre-endowed couples with the characteristics of "door-to-door couples", and used to mainly control the spouse selection of children by family 
and family through "arranged marriage".

As early as the 18th century, foreign scholars began to focus on the study of government scale. Adam Smith put forward the theory of "small government" in 1776. He believed that government intervention in market economy would lead to the loss of efficiency. The role of government is to maintain public order and build public facilities. The theory of "small government" advocates that the scale of government is the smallest. After the 1930s, Keynesianism prevailed. Keynesianism advocated that the government should intervene in the economic operation to make up for the defects of market economy itself, that is, the theory of "big government" contrary to Adam Smith's "small government" theory. The noticeable prevailing view is that the size of government should be the size of government to maximize social welfare.

For the measurement and measurement of government size, Agasisti [5] believes that the measurement of government size depends on three key factors, including the ability of market economy, the need of market economy and the ability of government itself. Michael. L. Marlow proposed two quantitative indicators to measure the external scale of the government. They asked the absolute scale and the relative scale respectively. Among them, the absolute scale was measured by the total amount of government public expenditure. Wallace Oates argued that the absolute number of indicators could not reflect the real size of the government in different regions because of the different economic development level and economic strength of the governments. He proposed that it would be more meaningful to measure the size of government by relative index. Oates proposed to measure the size of the government by the proportion of government public expenditure in the total economic volume of the region. This index has also been recognized by many scholars at home and abroad, such as Barro, Kormendi, Meguire, Landau. However, J. Stephen Ferris and Edwin G. West proposed that the scale of government measured by non-transferable expenditure of government can more directly reflect the efficiency of resource allocation. Rajeev K. Goel, Michael A. Nelson [6] proposed to measure the size of government by the proportion of local government civil servants in the employed population. As for the research on the matching between government size and marriage, scholars at home and abroad seldom involve it.

\subsection{Chinese Studies}

Chinese scholars have made considerable in-depth studies on the matching of marriage choices. $\mathrm{Li} \mathrm{Yu} \mathrm{[7]} \mathrm{thinks} \mathrm{that} \mathrm{Chinese} \mathrm{traditional} \mathrm{society} \mathrm{pays} \mathrm{more} \mathrm{at-}$ tention to the same kind of matching of personal conditions, especially education, because education reflects the social economic status and cultural capital of individuals at the same time. From our research, education is one of the most important indicators of modern social stratification, which is more stable and easier than other indicators such as professional "income" reputation. The measurement has higher reliability. Li Yu [8] also found that since the 21st century, the importance of family background in the process of marriage matching in 
China has risen, which leads to the deviation of marriage matching model from industrialization theory in China. Such a change is also a reflection of the changing trend of social value orientation.

Feng Xiaotian [9] study found that income matching is an important factor affecting marriage choice in major cities in China. Married young couples in China have a higher degree of income matching. In addition, there is a high correlation between individual income and occupation, which also leads to a high coincidence between income matching and occupation matching.

The household registration system is also a factor with Chinese characteristics. For a long time, the household registration system is an important reason for the difference between urban and rural areas in China. For marriage matching, the issue of household registration also plays an important role. Lu Yilong [10] pointed out that although the household registration system is constantly improving and reforming, the phenomenon of similar household registration marriage is very prominent at present. Urban household registration and rural household registration have become a difficult gap between marriage choices. Zhang Yi [11] believes that family background plays a decisive role in marriage choice, and family background mainly reflects both parents' educational level and occupation. These two aspects play an inertial role in the career and education of future generations. On one point, $\mathrm{Li} \mathrm{Yu} \mathrm{[12]} \mathrm{has} \mathrm{a} \mathrm{similar} \mathrm{point} \mathrm{of} \mathrm{view.}$

Compared with "matching" marriage in marriage matching, Chinese scholars also have different views.

Shen Xinfeng [13] used the endogenous family negotiation model to analyze the gradient matching and structural imbalance in China's current marriage matching market. He believed that because of the traditional gender division of labor and family status in China, women were more given the job of raising children. This biological difference led to the mismatch in marriage matching, and women chose more upward. Match, but men don't. Wu Yaowu and Liu Qian [14] argue that the general increase in women's educational years delays women's entry into the marriage market, which directly reduces their chances of finding better educated spouses in the process of marriage matching.

Chinese scholars have different views on the definition of the size of the Chinese government. Lei Aixian [15] proposed that in the context of the socialist market economy with Chinese characteristics, compared with private expenditure, government size refers to government expenditure to meet public needs. Wang Zuming [16] pointed out that the size of government can be measured from the quantitative dimension of government institutions, and proposed that the size of government refers to the number of organizations and posts set up corresponding to the government organs that manage a certain geographical area and population.

Other Chinese scholars believe that the right and intelligent allocation of government is the fundamental measure of government size. Lu Xiangguo [17] proposed that the scale of government should cover both internal and external scales. The internal scale mainly reflects the functions and powers of the gov- 
ernment. The external scale is divided into three aspects: personnel scale, organization scale and cost scale. At the same time, the external scale of government is the material carrier of the internal scale of government. In addition, Zhang Jun proposed that the size of government is the sum of all levels of government and various departments, and constructed in accordance with certain organizational principles. Wang Xueqing [18] put forward a different definition of government size-the scope of activities determined by government agencies and government behavior costs.

For the measurement of government size, the Chinese scholar Wang Yuming [19] pointed out that the measurement of government size is determined by the scale of government functions and powers, government expenditure, the number of government employees, and the size of government institutions. Liu Lin, Liu Guangda [20] and other scholars measure the size of the government in terms of the total amount of extra budgetary expenditure, the total amount of expenditure within the budget, government consumption expenditure and government revenue. Similarly, Chinese scholars also proposed that we should try to use relative index to truly reflect the size of the government. Guo Yuemei [21] advocated that the government scale be measured by the proportion of Government Civil Servants in employment. Pan Weijie [22] used the proportion of government expenditure to GDP to measure the size of the government.

\section{Data And Key Definition}

\subsection{Data}

The data used in this paper are from the survey data of China General Social Survey in 2013, CGSS2013. China General Social Survey is the first national, comprehensive and continuous large-scale social survey project implemented by Renmin University of China and Hong Kong University of Science and Technology. Since 2003, an annual survey has been conducted on individuals from 125 counties (districts), 500 streets (townships and towns), 1000 residential (village) committees and 10,000 families in China. By collecting data from all aspects of Chinese and Chinese society regularly and systematically, this paper summarizes the long-term trend of social change, explores social issues of great theoretical and practical significance, promotes the openness and sharing of domestic social science research, and provides data for international comparative research. The CGSS survey data and other survey data are completely open to the whole society. Their data have a significant impact at home and abroad, and are regarded as one of the most important data sources for the study of China. For missing values in data, we delete the missing samples of key information and replace the numerical variables with the average values of samples.

CGSS2013 is the latest data released by China's comprehensive social survey, covering the Tibetan Autonomous Region except Tibet. Administrative units of Xinjiang Uygur Autonomous Region, Hainan Province and all provinces, municipalities directly under the Central Government and autonomous regions out- 
side Hong Kong, Macao and Taiwan. In each county (district) level administrative unit, four residential (village) committees were randomly selected and 25 families were investigated. A questionnaire survey was conducted by randomly selecting one person from each selected family. The total sample size of CGSS2013 was 11,438. Among them, primary sampling units (county districts) and secondary sampling units (village committees and neighborhood committees) are selected to do paper work with demographic data; while in the village committees and neighborhood committees, the mapping method is used to sample the households to be investigated; in the household survey, the KISH table is used to sample the households. To sum up, China's comprehensive social survey is a representative, extensive and persuasive data source, which has important research value and has been widely used by scholars domestic and international.

\subsection{Key Definition}

The cadre family in this paper means that at least one parent in the family is in a government department or a public institution affiliated to the government, which is what we call a "public institution". Based on the domestic public institutions accept government leadership, engaged in education, science and technology, culture, health and other activities of social service organizations. Although it does not belong to the government, it still has some power and influences the daily life of the public in many ways. By the China banking regulatory commission (CBRC), China securities regulatory commission (CSRC), China insurance regulatory commission, the three institutions, for example, the three institutions does not belong to the government unit, but is responsible for the financial insurance industry such as rules and regulations, this has important implications for the operation in China. Therefore, this paper defines the situation of working in public institutions and government departments as the cadre family. Moreover, since political ties or resources do not disappear once they are established, such as retired cadres whose social networks still include government workers, they can still be used. Therefore, children in cadre families in this paper are defined as those whose parents work in government departments or public institutions around the age of 14. Based on the staffing system of the Chinese government, only a very small proportion of personnel are transferred from "non-cadres" to "cadres" in middle age. Such a definition is of more practical significance than the definition of whether the parents in the year of marriage work in a government department or public institution.

\section{Model and Empirical Analysis}

\subsection{The Model}

In order to make further empirical analysis of the above phenomena, this paper uses the regression models which draw on the research method of Lan [23] to make empirical analysis of the difference in the possibility of marriage match between cadres and their family background compared with ordinary family 
background. The specific model is as follows:

$$
\begin{aligned}
Y_{i p}= & \alpha+\beta_{1} \text { Cadrebackground }_{i p} * \text { Govsize }_{p}+\beta_{2} \text { Govsize }_{p} \\
& +\beta_{3} X_{i p}+\text { Province }_{p}+\varepsilon_{i p}
\end{aligned}
$$

The explained variable $Y_{i p}$ was a binary variable. When the sample reached a marriage with a spouse working in a government department or public institution, the value was 1 , otherwise it was 0. Cadrebackground $_{i p}$ represents whether individual I from p province has cadre family background, and the value of having cadre family background is 1 , otherwise it is zero. Govsize ${ }_{p}$ represents the size of the government of $\mathrm{p}$ provinces and regions. Because an individual's marriage decisions should be influenced by the size of the local government where they work and live, the province to which an individual belongs refers to the province where the individual conducts social activities, rather than the place of birth or household registration. The cross product term of the two is the explanatory variable, and the coefficient $\beta_{1}$ represents the influence of government size on the marriage matching between individuals from ordinary family background and those working in government departments or institutions. Coefficient $\beta_{2}$ represents the influence of government size on the likelihood of marriage match between individuals with cadre family background and those working in government departments or institutions and children of ordinary families. Considering the need to control various aspects of characteristics of different provinces, such as traditional marriage customs, economic environment, cultural differences and other factors, in addition, the number of cadres in different provinces also affects the possibility of marriage matching between individuals and cadres, so the dummy variable Province $_{p}$ in different provinces is set to achieve the purpose. In addition to explanatory variables, there are many different factors influencing the choice of marriage match. In this paper, five factors including occupation matching, education degree matching, household registration matching, ethnic information matching and gender were selected as control variables according to the theories related to marriage matching and the studies of domestic and foreign scholars. In this paper, CGSS2013 data was used, and the total number of samples excluding the samples with missing key variables was 3953. The description and statistics of variables are shown in Table 1. It can be seen that the number of people with cadre family background in the sample is up to $15 \%$ of the total, the matching rate of occupation is low at $16.6 \%$, the matching rate of education degree is $42.4 \%$, and the matching rate of household registration and ethnic status is high at about $90 \%$.

The model (1) does not reflect the influence of the time and year of marriage between an individual and a spouse in a government department or institution on their marriage matching. However, the government's fiscal expenditure fluctuates greatly with time. It changes dramatically in different years in the same region, which also leads to the change of the size of the government. If the size of resources and rights controlled by the government increases in a certain period of time, it will inevitably affect factors such as political ties, value and social 
Table 1. The description and statistics of variables.

\begin{tabular}{cccccc}
\hline Variable Name & Sample Size & Mean & Std & Minimum & Maximum \\
\hline Cadre family background & 3953 & 0.148 & 0.355 & 0 & 1 \\
Career matching & 3953 & 0.166 & 0.373 & 0 & 1 \\
Government size & 3953 & 0.138 & 0.044 & 0.084 & 0.332 \\
Education matching & 3953 & 0.424 & 0.494 & 0 & 1 \\
Household registration matching & 3953 & 0.893 & 0.309 & 0 & 1 \\
Gender & 3953 & 0.531 & 0.483 & 0 & 1 \\
Ethnic matching & 3953 & 0.928 & 0.258 & 0 & 1 \\
\hline
\end{tabular}

status of "cadres" positions in that period, and thus have different degrees of impact on the possible new and time of "marriage" between children of cadres" families and spouses serving in government departments or institutions. In order to take the time factor into account, this paper extends the model (1) to the model (2), taking the year of marriage and the size of the government of each sample as important indicators. The model (2) will include those who have achieved marriage matching after the reform and opening-up, namely from 1978 to 2013.

$$
\begin{aligned}
Y_{i p t}= & \alpha+\beta_{1} \text { Cadrebackground }_{i p t} * \text { Govsize }_{p t}+\beta_{2} \text { Govsize }_{p t} \\
& +\beta_{3} X_{i p}+\text { Province }_{p} * \text { time }_{t}+\varepsilon_{i p t}
\end{aligned}
$$

$Y_{i p t}$ is a binary variable. Sample I from P province has a marriage value of 1 with spouses working in government departments or institutions in $t$ year, otherwise I $t$ is 0 . Govsize ${ }_{p t}$ represents the size of the local government in $t$ year. Considering the differences of marriage culture, economic environment and social customs in different provinces and regions in different periods, the crossdummy variables of provinces and time are added to the model to control the differences. The selection of control variables is the same as that of model (1). Five factors are selected as control variables: occupation matching, education matching, household registration matching, ethnic information matching and gender matching. Using CGSS2013 data, the total number of samples excluding the missing key variables is 3604 . The descriptive statistics of variables are shown in Table 2. It can be seen that the average age of marriage is 24.227 , the minimum age of marriage is 15 , and the maximum age is 56 (second marriage). The average marriage year was in 1997, and the average size of government in individual marriage year was 0.128 , which was smaller than the average in model (1). Education matching, occupation matching, household registration matching and ethnic matching are similar to those in model (1).

Considering that the influence of government size on public value orientation is not immediate, that is, if the scale of government in that year increases, it will not immediately affect the social and economic behavior in that year. The impact of government size on the public is similar to that of social concepts. It is the size of government that has influenced public decision-making in the past period of time. Scholars at home and abroad usually use the lagging government 
Table 2. The description and statistics of control variables.

\begin{tabular}{cccccc}
\hline Variable Name & Sample Size & Mean & Std & Minimum & Maximum \\
\hline Cadre family background & 3.604 & 0.155 & 0.362 & 0 & 1 \\
gender & 3.604 & 0.529 & 0.483 & 0 & 1 \\
Marriage age & 3.604 & 24.227 & 3.561 & 15 & 56 \\
Government size & 3.604 & 0.128 & 0.059 & 0 & 0.612 \\
Education matching & 3.604 & 0.424 & 0.494 & 0 & 1 \\
Household registration matching & 3.604 & 0.891 & 0.312 & 0 & 1 \\
Marriage year & 3.604 & 1996.91 & 9.212 & 1978 & 2013 \\
\hline
\end{tabular}

scale as a variable in their research on government scale and macro-economy. This paper argues that, unlike macro-economy, from a micro perspective, the speed at which individuals respond to the size of the government will be slower than that of the national macro-economy as a whole, that is, the size of the government in the previous year cannot immediately affect marriage matching. Therefore, in this model, we use the lagged scale of government and the average size of local government in the past five years to measure the scale of government. The model is as follows:

$$
\begin{aligned}
Y_{i p t}=\alpha & +\beta_{1} \text { Cadrebackground }_{i p t} * \text { Govsize }_{p t-1}+\beta_{2} \text { Govsize }_{p t-1} \\
+ & \beta_{3} X_{i p}+\text { Province }_{p} * \text { time }_{t}+\varepsilon_{i p t} \\
Y_{i p t}= & \alpha+\beta_{1} \text { Cadrebackground }_{i p t} * \text { Govsize }_{p \bar{t}}+\beta_{2} \text { Govsize }_{p \bar{t}} \\
& +\beta_{3} X_{i p}+\text { Province }_{p} * \text { time }_{t}+\varepsilon_{i p t}
\end{aligned}
$$

\subsection{Empirical Results and Analysis}

The results of model (1) are consistent with that of model (2) (3) (4). The regression results of model (2) are shown in Table 3 (including not adding control variables and adding control variables):

As for the control variables, we can see that gender has a significant positive impact on the possibility of marriage matching between individuals and individuals working in government departments or institutions, indicating that during this period, women are more inclined to match with individuals working in government departments or institutions. This phenomenon is in line with the reality of Chinese society. In the marriage market, the work of government departments or institutions is widely considered to be more prominent in social status, stability, economic income and other aspects. Therefore, "cadres" are preferred in the marriage market, especially in the dating market. In addition, gender inequality and different social status in China's marriage market have led to the enhancement of women's bargaining power in the process of marriage matching. In terms of career choice, women have more power to choose "cadres" as marriage matching objects. All these factors lead to women's preference for marriage matching with individuals working in government departments or 
Table 3. The regression results of models.

\begin{tabular}{|c|c|c|c|c|c|c|}
\hline Model & (1) & (2) & (3) & (4) & (5) & (6) \\
\hline $\begin{array}{c}\text { Cadre family } \\
\text { background }{ }^{\star} \\
\text { Government size }\end{array}$ & $4.2123^{* * *}$ & & & $4.1873^{* * *}$ & & \\
\hline Government size & -0.0948 & & & -0.6376 & & \\
\hline $\begin{array}{c}\text { Cadre family } \\
\text { background }{ }^{*} \text { Lagging } \\
\text { government size }\end{array}$ & & $3.9571^{\star * *}$ & & & $3.9931^{\star * *}$ & \\
\hline Lagging government size & & 0.4979 & & & -0.3454 & \\
\hline $\begin{array}{c}\text { Cadre family } \\
\text { background }{ }^{*} \text { Average } \\
\text { government size } \\
\text { over } 5 \text { years }\end{array}$ & & & $3.3788^{* * *}$ & & & $4.1521^{\star \star *}$ \\
\hline $\begin{array}{l}\text { Average government } \\
\text { size over } 5 \text { years }\end{array}$ & & & -0.1716 & & & -0.7894 \\
\hline Career matching & & & & $0.1732^{* *}$ & $0.1808^{\star * *}$ & $0.1796^{* * *}$ \\
\hline Education matching & & & & $-0.1251^{* *}$ & $-0.1316^{\star \star}$ & $-0.1321^{\star *}$ \\
\hline $\begin{array}{c}\text { Household } \\
\text { registration matching }\end{array}$ & & & & -0.0555 & -0.058 & -0.0543 \\
\hline Ethnic matching & & & & 0.0708 & 0.0614 & 0.0714 \\
\hline gender & & & & $-0.1448^{\star * *}$ & $-0.1465^{\star * *}$ & $-0.1456^{* * *}$ \\
\hline Constant term & $1.0817^{\star * *}$ & $1.1490^{* * *}$ & $1.0493^{\star * *}$ & $-0.7668^{* *}$ & $-0.7910^{\star *}$ & 0.1795 \\
\hline Fixed effects & Yes & Yes & Yes & Yes & Yes & Yes \\
\hline $\mathrm{N}$ & 3604 & 3604 & 3604 & 3604 & 3604 & 3604 \\
\hline $\mathrm{R} 2$ & 0.0298 & 0.0271 & 0.0222 & 0.0779 & 0.0747 & 0.0752 \\
\hline
\end{tabular}

${ }^{a}$ Standard errors in parentheses. ${ }^{b *} \mathrm{p}<0.10,{ }^{* *} \mathrm{p}<0.05,{ }^{* * *} \mathrm{p}<0.01$.

institutions.

The matching variable of education level is negatively correlated with the possibility of marriage matching between individuals and those working in government departments or institutions, which indicates that the matching of one party's education level with the other party's education level reduces the possibility of marriage matching. This phenomenon is somewhat different from what was expected, but it is quite reasonable. Because "cadres" are often regarded as "golden rice bowl" professions, at the same time, these posts also have higher requirements for academic qualifications, for example, most of the cadre recruitment now requires undergraduate graduation or above. Data also show that the proportion of individuals (61.08\%) who work in government departments or institutions with higher education is much higher than the average. The common phenomenon of "cadres" with high academic qualifications poses a natural obstacle to the achievement of educational matching between husband and wife. In addition to this factor, the higher proportion of male cadres $(60 \%)$ means that more women need the same level of education to achieve marriage matching. 
After the expansion of the college entrance examination in 1999, the increase of Chinese women's educational level delayed their entry into the marriage market, which also reduced the possibility of women searching for husbands with equal or higher educational level [14], which indirectly led to this phenomenon.

The matching results of ethnic information and the nature of household registration show that the relationship between ethnic information and the possibility of marriage matching with individuals working in government departments or institutions is not significant, because the matching rate of ethnic information and the nature of household registration is very high, and more than $90 \%$ of marriages are matched by these two factors, so this also leads to the result is not significant.

Career matching has a significant positive correlation with the likelihood of marriage matching between sample individuals and those who work in government departments or institutions, which indicates that if individuals and those who work in government departments or institutions are in the same profession or position, the likelihood of marriage matching will be increased. This conclusion does not differ from our understanding. After the reform and opening up, the proportion of husband and wife with the same occupation has gradually increased, and people are more inclined to choose individuals with similar occupation as spouses. The same occupation also means similar living conditions, skills learning experience and more similarities among individuals. These factors will lead to a positive impact of career matching on marriage. Compared with other professions, the situation of "cadres" in this field is the same. Being in the same profession as individuals working in government departments or institutions increases the likelihood of marriage matching.

In all the regression models, the factors such as educational background, household registration, occupation, nationality and gender are taken as control variables. The regression results show that the coefficient of government size is not significant, indicating that the possibility of marriage matching between individuals with general family background and those working in government departments or institutions is not substantially affected by government size. In the model, the cross-term coefficients of government size and civil servants' family background are significant. Because the coefficients in the probit regression model have no economic significance, it is necessary to analyze the marginal effects of variables, and the results of the marginal effects are shown in Table 4. The marginal effect of the transfer item between the size of government and the family background of civil servants on the likelihood of marriage matching with individuals working in government departments or institutions is 0.9193 and 0.9877, which is much larger than other variables in each model. In model (4), the marginal effect coefficient means that when the size of government is expanded by 0.1 units, the likelihood of marriage matching between the children of civil servants' families is increased by $9.43 \%$ (model (6) 9.66\%) compared with those of individuals with ordinary family background and those working in government departments or institutions. This shows that the greater the economic 
Table 4. Marginal effects of significant variables.

\begin{tabular}{ccccccc}
\hline Marginal effect & Model 1 & Model 2 & Model 3 & Model 4 & Model 5 & Model 6 \\
\hline Interchange item & 0.9387 & 0.9411 & 0.9877 & 0.9435 & 0.9193 & 0.9657 \\
Career matching & & & & 0.03974 & 0.04087 & 0.04466 \\
Education matching & & & & -0.02826 & -0.02976 & -0.32622 \\
gender & & & & -0.03283 & -0.03318 & -0.03671 \\
\hline
\end{tabular}

resources and influence controlled by the local government, the more likely the individuals with family background of civil servants will be able to "marry" with the individuals who serve in government departments or institutions. This is consistent with the phenomena stated in the previous chapter of the article.

In the model (1) - (6), the possibility of marriage matching between ordinary family children and civil servants by government size is not significant, which indicates to some extent that the resources controlled by the government and the role played by the government in the economic society are not mainly through influencing the attractiveness of the position of "civil servant" in the marriage matching market, thus affecting individuals and government departments. Or the possibility of marriage matching among individuals in public institutions has an impact, that is, the increasing size of the local government will not make the public think that "civil servants" have more advantages in the marriage market, nor will it result in the rising social status and prestige of "civil servants" and prefer to choose "civil servants" as spouses. The multiplier coefficient of the family size of cadres and the size of government are both positive and significant. Combined with the significance of the coefficient of the double difference model, we can conclude that the marriage decision of the children of the family size of cadres is influenced more by the political resources and ties. The long-term employment of parents of cadres' children has accumulated certain political relations with government departments and institutions, which are similar to social capital, which arises from certain political and social networks and brings positive help to their individual social and economic activities (Yang Ruilong 2010). In China, the role of parents in marriage is very important. The object of individual marriage matching is influenced to a certain extent by their parents. In traditional Chinese marriage, matching and introduction of relatives and friends are common and effective ways to achieve marriage matching. Through their parents' social resources, individuals will have more potential matching for cadres than those who do not have family background of cadres. Object. When the scale of government expands, this kind of political relationship will expand at the same time, that is, the social capital and political social network of cadres will expand, which provides more ways and opportunities for their children to match with individuals in government departments or institutions, such as more "cadres" as choices when introducing their children to each other. Thus, the possibility of marriage matching between cadres' children and individuals working in government departments or institutions is improved. On 
the other hand, when the scale of the government expands, the value of this social capital will increase and bring greater benefits to family members. From the perspective of rational people, children of cadres' families will be more inclined to "marry" with individuals serving in government departments or institutions to expand their political relations, so that families will get greater benefits. The next part of this paper will make further empirical analysis on its transmission mechanism.

\section{Conduction Mechanism and Empirical Analysis}

The previous part of the article suggests that the size of the government affects the choice of marriage for cadres' children by acting on political relations. This part of the paper is an empirical analysis to verify that when the government expands, this political relationship and its value will expand at the same time. However, the direct measurement of this political relationship is not scientific, so the article attempts to validate it from other aspects and propose two reasonable assumptions:

1) When political relations and their value expand, cadres' children will think that political relations are more important for personal success.

2) When political relations and their values expand, the income of cadres' families will also increase. This paper attempts to prove the importance of political relations, the relationship between family income and government size through empirical analysis, and then demonstrate the relationship between political relations and government size.

\subsection{Evaluation of the Importance of Political Relations}

This paper suggests that when the size of government expands, the political relationship and value of cadre families will expand accordingly, thus affecting their children's marriage match. If the value and benefits of political relations increase as the size of the government increases, this paper believes that for individuals, the importance of political relations will increase accordingly. This part of the paper attempts to prove that the evaluation of the importance of political relations by cadres' children will be enhanced with the expansion of the government, so as to demonstrate political relations and the increase of their value.

Respondents of the China General Social Survey were asked randomly to rate how important they thought political connections are to success. There are six choices in the questionnaire, which are "very important", "relatively important", "generally important", "not so important", "not at all important" and "unable to choose". This article will assign values to each of the five options except the "unable to choose", which is very important at 5 , not important at all at 1 , and so on. The data showed that 35 percent of respondents rated political connections as more important to personal success, with the highest percentage. Only 2.95 percent of respondents said that political connections were not important to personal success. The population mean was 3.56, indicating that the public generally believed that political relations had a great influence on personal success. 
For comparison, the average public rating of the importance of hard work for personal success was 4.20 , higher than the average for political relationships. This dovetails with the perception that our efforts are more important than political connections. For the children in the cadre family discussed in this paper, their average evaluation of the importance of political relations is 3.61, which is slightly higher than the overall sample.

In order to further prove that the expansion of government size leads to the increase of the political relationship of cadre families and its value, this paper makes an empirical analysis of the relationship between government size and the public's importance to political relations by using the previous model.

evaluation $_{i p}=\alpha+\beta_{1}$ Cadrebackground $_{i p}+\beta_{2}$ Cadrebackground $_{i p} *$ Govsize $_{p}$

$$
+\beta_{3} X_{i p}+\text { province }_{p} * \text { cohort }_{t}+\varepsilon_{i p t}
$$

evaluation $_{i p}$ represents the subjective evaluation of the importance of political relations of sample I from province $\mathrm{p}$ (from 1 to 5), the other variables are consistent with the previous model. Factors such as individual gender, education level and occupation were taken as control variables.

Considering that the concept and evaluation of politics are different due to the ideological and cultural differences and economic environment of different provinces, and this difference will also change with different ages. Therefore, the fixed effect of the cross term of province dummy variable and age dummy variable are added into the model to control it. The regression results are shown in Table 5.

The regression results are shown in Table 5, with the expansion of the government scale, the children of cadres will evaluate the importance of political relations for personal success more highly than those from ordinary family background. Its coefficient indicates that when the government scale increases by $10 \%$, the evaluation of the importance of cadres' children on political relations will increase by 0.2 units (the maximum value is 5). Thus, we can draw the following conclusion: when the government expands, children of cadres consider political relations more important than individuals from different family backgrounds. On the basis of hypothesis 1 , we can get that political relations and their values

Table 5. The regression results.

\begin{tabular}{cccc}
\hline Variable name & $(1)$ & $(2)$ & $(3)$ \\
\hline Cadre family background & -0.2189 & -0.2592 & -0.2592 \\
Cadre family background ${ }^{*}$ government size & $1.8649^{*}$ & $2.0073^{\star}$ & $2.0073^{\star *}$ \\
Constant term & $3.5522^{\star * *}$ & $3.6647^{\star * *}$ & $3.6647^{\star * *}$ \\
Control variables & No & Yes & Yes \\
Fixed effects & No & No & Yes \\
$\mathrm{N}$ & 2950 & 2950 & 2950 \\
$\mathrm{R} 2$ & 0.001 & 0.004 & 0.004 \\
\hline
\end{tabular}

${ }^{\mathrm{a}}$ Standard errors in parentheses. ${ }^{\mathrm{b}} \mathrm{p}<0.10,{ }^{* *} \mathrm{p}<0.05,{ }^{* * *} \mathrm{p}<0.01$. 
expand with the expansion of the government.

\subsection{Revenue and Government Size}

For hypothesis 2, this paper believes that when the value of government relations increases, individuals can benefit in many ways, and income is one of the most important aspects. Therefore, this paper attempts to prove from the perspective of income that the expansion of government size has a positive impact on the value of political relations. In view of the fact that the political identity of an individual's parents not only have an impact on his/her personal income, but also may have an impact on the income of his/her spouse, this paper selects the annual income of both husband and wife as the explained variable.

From the China General Social Survey in China, we can get the full year income of the sample in 2012. According to the national regulations, the male retirement age is 60 years old and the female retirement age is 55 years old. After the retirement individual is removed, the average annual income of the sample is $72,093.36$ yuan, and the average annual income of his husband and wife with a family background of cadres is 101,484.79 yuan. Yang Ruilong [24] pointed out in his research that the political identity of parents has a positive effect on their personal income, and proves that this positive influence is through political relations by controlling whether their parents are employed. This conclusion can also be verified to some extent from this set of data. Based on this, this paper explores whether this effect has changed when the government expands. This paper draws on the model in its article and considers the size of the government. Because the wage levels of different industries in different provinces are very different, the article adds dummy variables based on provinces and industries to control this difference. The logarithmic form of annual income is used as the explanatory variable. The double difference model is used to analyze the impact of changes in government size on the annual income of individuals with a cadre family background.

$$
\begin{aligned}
\text { logincome }_{i p}= & \alpha+\beta_{1} \text { Cadrebackground }_{i p}+\beta_{2} \text { Cadrebackground }_{i p} * \text { Govsize }_{p} \\
& +\beta_{3} X_{i p}+\text { area }_{p}+\text { industry }_{q}+\varepsilon_{i p}
\end{aligned}
$$

The regression results are shown in Table 6:

It can be seen from the results that the coefficient of the cross-multiplication term between the cadre family background and the government scale is positive, and the results are significant, indicating that when the government scale expands by 0.1 units, the annual income of the sample with the cadre family background will increase by $13.42 \%$ compared with the sample without the cadre family background. According to the regression results, we can get that when the government scale is expanded, the income of the parents of cadres' children has an additional increase compared with that of ordinary families. On the basis of hypothesis 2 , we can consider that political relations and their values expand with the expansion of government size. 
Table 6. The regression results.

\begin{tabular}{ccc}
\hline Variable name & $(1)$ & $(2)$ \\
\hline Cadre family background & -0.083 & -0.1207 \\
Cadre family background ${ }^{\star}$ government size & $1.5675^{\star * *}$ & $1.3421^{\star * *}$ \\
Constant term & $10.2726^{* * *}$ & $10.6726^{* * *}$ \\
Control variables & No & Yes \\
Fixed effects & Yes & Yes \\
$\mathrm{N}$ & 2010 & 2010 \\
$\mathrm{R} 2$ & 0.258 & 0.312 \\
\hline
\end{tabular}

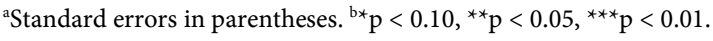

\section{Robustness Check}

In order to make the empirical regression results more convincing, this part of the article replaces the original indicators (government expenditure/GDP) with different indicators of government size to test the robustness of the empirical results. In the domestic research on the scale of government, besides the index selected in the article, some scholars take the ratio of government consumption to GDP of the province (Chen Taiming, 2018) as the index to measure the scale of local government. Therefore, this paper also chooses the ratio of local government consumption to GDP as the robustness test index to replace the original index and make relevant analysis. Government consumption expenditure refers to the consumption expenditure of public services provided by government departments for the whole society and the net expenditure of goods and services provided to residents free of charge or at a lower price. The former equals the output value of government services minus the value of operating income obtained by government units; the latter equals the goods and services provided by government departments to residents free of charge or at a lower price. Market value minus the value charged to households. Government consumption mainly includes the following four parts: the part of expenditure in the budget used for public needs belongs to the recurrent business expenditure; the part of expenditure in the extrabudgetary budget belongs to the recurrent business expenditure; the virtual depreciation of fixed assets of administrative units and non-profit institutions; the urban residents' Committee and the rural farmers' committee which are not included in the national budget. Operational expenditure.

From the regression results, it can be concluded that there is no difference between the empirical analysis with the proportion of government consumption as an indicator of government size and the results with the proportion of fiscal expenditure as an indicator, and the significant and negative coefficients of the key variables are consistent. Thus, we can conclude that the empirical results of this paper are robust. The specific regression results are shown in Table 7. 
Table 7. The regression results of models.

\begin{tabular}{|c|c|c|c|c|c|c|}
\hline Model & (1) & (2) & (3) & (4) & (5) & (6) \\
\hline $\begin{array}{c}\text { Cadre family } \\
\text { background }{ }^{*} \\
\text { Government size }\end{array}$ & $4.7649^{* * *}$ & & & $4.7078^{\star * *}$ & & \\
\hline Government size & -0.7646 & & & -0.8545 & & \\
\hline $\begin{array}{c}\text { Cadre family } \\
\text { background }{ }^{\star} \text { Lagging } \\
\text { government size }\end{array}$ & & $4.7833^{* * *}$ & & & $4.7259^{\star \star *}$ & \\
\hline Lagging government size & & -0.8777 & & & -0.9663 & \\
\hline $\begin{array}{l}\text { Cadre family } \\
\text { background }{ }^{\star} \text { Average } \\
\text { government size } \\
\text { over } 5 \text { years }\end{array}$ & & & $4.8490^{\star * *}$ & & & $4.7992^{\star * *}$ \\
\hline $\begin{array}{l}\text { Average government } \\
\text { size over } 5 \text { years }\end{array}$ & & & -0.9578 & & & -1.0516 \\
\hline Career matching & & & & $0.1819^{* * *}$ & $0.1841^{\star * *}$ & $0.1843^{* * *}$ \\
\hline Education matching & & & & $-0.1286^{\star *}$ & $-0.1285^{\star *}$ & $-0.1300^{* *}$ \\
\hline $\begin{array}{l}\text { Household } \\
\text { registration matching }\end{array}$ & & & & -0.0879 & -0.0877 & -0.0882 \\
\hline Ethnic matching & & & & 0.0305 & 0.0244 & 0.0231 \\
\hline gender & & & & $-0.1409^{* *}$ & $-0.1404^{\star *}$ & $-0.1421^{\star *}$ \\
\hline Constant term & $-1.1394^{* * *}$ & $-1.1367^{\star * *}$ & $-1.1358^{\star * *}$ & $-0.9731^{\star * *}$ & $-0.9698^{\star * *}$ & $-0.9641^{\star * *}$ \\
\hline Fixed effects & Yes & Yes & Yes & Yes & Yes & Yes \\
\hline $\mathrm{N}$ & 3604 & 3604 & 3604 & 3604 & 3604 & 3604 \\
\hline R2 & 0.0332 & 0.0332 & 0.0332 & 0.0407 & 0.0407 & 0.0408 \\
\hline
\end{tabular}

${ }^{a}$ Standard errors in parentheses. ${ }^{b *} \mathrm{p}<0.10,{ }^{* *} \mathrm{p}<0.05,{ }^{* * *} \mathrm{p}<0.01$.

\section{Conclusion}

Based on the survey data of China General Social Survey in 2013 and the characteristic data of all provinces in China, this paper establishes multiple regression models and probit regression to study the relationship between the size of government and marriage matching of children of cadres' families and its mechanism. The results show that apart from the traditional factors affecting marriage matching, the size of government has a significant impact on the spouse occupation of children of cadre families. When the size of government is larger, children of cadre families are more likely to match marriage with individuals of cadre occupation than children of non-cadre families. From the results of the models, it can be concluded that the above phenomenon is not caused by the change of the attractiveness of the "cadre" occupation with the change of the size of the government. Therefore, this paper argues that the impression of the size of the government on the individual marriage is more through the influence of the value and size of the political ties and then the role of marriage matching. It is also found that the educational level, occupation and gender of an individual 
may affect the possibility of marriage matching with a cadre. In summary, the influence of government size on individuals with cadres' family background is mainly through political resources and connection. When the scale of the government expands, the political resources and ties of cadres' families will also expand, which will bring more ways and possibilities for them to achieve marriage matching with those who are professional cadres. In addition, when the size of the government expands, the value of this social capital increases and can bring greater benefits to family members, which will also drive them to marry individuals who work as cadres. This paper also verifies that when the size of the government expands, the political relationship between cadres and families will also expand through subjective evaluation of the importance of the sample to political relations and family income. The results show that when the scale of government expands, individuals with family background of cadres have an additional increase in their subjective evaluation of political importance than those with ordinary family background. That is, they think that political resources are more important when the scale of government expands. When the scale of government expands, the family income of individuals with cadre family background will increase, which also proves that the value of political ties will increase when the scale of government expands.

\section{Conflicts of Interest}

The author declares no conflicts of interest regarding the publication of this paper.

\section{References}

[1] Pan, X.Z. and Yan, H.G. (2016) Micro-Simulation Analysis of China's Personal Income Tax Reform. Taxation and Economy, 2, 67-72.

[2] Rosenfeld, M.J. (2008) Racial, Educational and Religious Endogamy in the United States: A Comparative Historical Perspective. Social Forces, 87, 1-31. https://doi.org/10.1353/sof.0.0077

[3] Mare, S.R.D. (2005) Trends in Educational Assortative Marriage from 1940 to 2003. Demography, 42, 621-646. https://doi.org/10.1353/dem.2005.0036

[4] Abramitzky, R., Delavande, A. and Vasconcelos, L. (2011) Marrying Up: The Role of Sex Ratio in Assortative Matching. American Economic Journal: Applied Economics, 3, 124-157. https://doi.org/10.1257/app.3.3.124

[5] Agasisti, T. and Salerno, C. (2007) Assessing the Cost Efficiency of Italian Universities. Education Economics, 15, 455-471. https://doi.org/10.1080/09645290701273491

[6] Goel, R.K. and Nelson, M.A. (1998) Corruption and Government Size: A Disaggregated Analysis. Public Choice, 97, 107-120. https://doi.org/10.1023/A:1004900603583

[7] Li, Y. and Lu, X.C. (2008) Homogeneity and Change of Spouse Selection-Matching of Autogeneity and Preference. Youth Studies, 6, 27-33.

[8] Li, Y. (2008) Educational Matching of Marriage: Fifty Years of Change. Population Science of China, 3, 24-59.

[9] Feng, X.T. (2012) Types of Marriage and Couple Relations among Youth: A Survey 
and Analysis of 1216 Married Youth in Five Cities of China. Social Science, 1, 87-94.

[10] Lu, Y.L. (2009) Would a "Door-to-Door" Marriage Be More Stable?-Empirical Analysis of Matching Structure and Divorce Risk. Population Study, 33, 81-91.

[11] Zhang, Y. (2003) Continuation of Intra-Class Marriage in China. Population Science of China, 4, 45-59.

[12] Li, Y. (2011) The Change of Marriage Matching: A Perspective of Social Openness. Sociological Research, 4, 122-136.

[13] Shen, X.F. (2011) Endogenous Family Negotiation and Marriage Matching. Economics (Quarterly), 10.

[14] Wu, Y.W. and Liu, Q. (2015) The Impact of College Enrollment Expansion on Marriage Market: Left-Behind Women? Left-Behind Men? Economics (Quarterly), 1, 5-30.

[15] Lei, A.X. (2002) Let Sunshine Come in Managing Land and Government Functions. China Land, 7, 13-15.

[16] Wang, Z., Wu, R. and Jin, Y. (2004) Reasons for the Expansion of Government Scale and Reform Principles in China. Journal of Chongqing University of Posts and Telecommunications, 16, 65-66.

[17] Lu, X. (2001) Rational Thoughts on the Moderation of Government Scale. Learning Forum, No. 10, 17-19.

[18] Wang, X. (2005) Analysis and Research on the Scale Expansion of Chinese Government. Foreign Economic and Trade, No. 6, 26-27.

[19] Wang, Y. (1998) On the Scale of Government and Its Rational Scale. Local Government Management, No. 9, 18-26.

[20] Liu, L. (2005) A New Indicator of Government Size. Contemporary Finance and Economics, No. 5, 53-57.

[21] Guo, Y. (2008) The Relationship between the Scale of Local Government and the Volatility of Output: Empirical Analysis of China. Fiscal Research, No. 7, 41-43.

[22] Pan, W. (2007) Quantitative Study on the Factors Affecting the Scale of Provincial Local Government. Journal of Public Administration, 4, 33-41.

[23] Lan (2013) Red Capitalism: Cadre Parents and Entrepreneurial Children in China. Working Paper, Fudan University, Hangzhou.

[24] Yang, R. (2010) Father's Political Identity, Political Relations and Children's Income. Economics, 9, 871-890. 